Annals of Glaciology $5 \quad 1984$

(c) International Glaciological Society

\title{
MODELING THE OCEAN IN CLIMATE STUDIES
}

by

Albert J. Semtner Jr.

(National Center for Atmospheric Research, P.O. Box 3000, Boulder, Colorado 80307, U.S.A.)

\begin{abstract}
A number of processes in the ocean must be modeled properly in order to produce valid estimates of oceanic heat transport, sea-surface temperature, and sea-ice extent in climate studies. These include: wind-driven turbulent mixing and water transport in the surface layer, internal vertical mixing due to several small-scale mechanisms, horizontal and vertical exchanges by mesoscale eddies, mixing along isopycnals, large-scale transport by currents, deep convection in polar regions, and boundary exchanges with atmosphere, ice, and land. Techniques to model these processes are described. Prospects are given for parameterizing the effects of phenomena that cannot be resolved in climate studies, particularly mesoscale eddies. Past simulations of the ocean in climate studies are reviewed. A modeling strategy is outlined for an improved treatment of the ocean, consistent with the computational power soon to be available.
\end{abstract}

\section{INT RODUCTION}

The purpose of this paper is to review the methodology and results of modeling the ocean in a climatic context and to suggest future modeling improvements. The paper summarizes a presentation to an audience of glaciologists and climatologists at an international symposium on ice and climate modeling, and it is not intended to be a comprehensive review of ocean climate modeling. Literature references on technical issues have been omitted for the sake of brevity, except in regard to the figures and tables. Those interested in review articles on various oceanic processes are referred to Warren and Wunch (1981).

The author has been involved primarily in modeling the three-dimensional circulation of the oceans, and this review reflects that orientation. It is assumed that most glaciologists and climatologists are interested in modeling climate on time scales as short as the seasonal cycle (because of the importance of summer melting) and as long as the replacement time of the deep world ocean $(\infty 800 \mathrm{a})$. It is also assumed that, although properties of ocean temperature and heat transport are desired mainly in the polar regions, nevertheless the oceanic connections of polar oceans with mid-latitude gyres and the linkage between the Arctic and Antarctic oceans through deep-water circulation will ultimately require ocean modeling on a global scale. The construction of a valid world ocean model is therefore taken as the methodological objective of ocean climate modeling. In the meantime, a number of simpler models will be employed to improve understanding of various issues; but these models will not be discussed here.

A number of important physical processes must be treated properly in a three-dimensional ocean model.
The first column of Table I lists these processes in five categories: (a) processes at the upper and lower ocean boundaries, (b) internal vertical mixing, (c) effects of mesoscale ocean eddies, (d) large-scale transports, and (e) miscellaneous $h$ igh-latitude effects. The next five sections of this paper will discuss these categories in turn from three viewpoints: how the processes are modeled in isolation, how well they are represented today in ocean models, and how they might be treated in improved models of the world ocean. Of the five categories, the one dealing with mesoscale eddy effects will be given the greatest emphasis.

\section{UPPER AND LOWER BOUNDARY PROCESSES}

It is well known that the ocean is capped by a relatively homogeneous layer which is stirred by wind forcing and by surface heat losses. Process models generally employ fine vertical resolution and governing equations based on higher-order turbulence closures to predict the time-dependent behavior near the surface. Most ocean models for climatic studies employ a constant-thickness mixed layer as a simplification. Variations of upper ocean heat capacity which affect surface temperature are neglected. An improvement is to embed a variable-thickness mixed layer in circulation models. A bulk formulation can be based on simple principles of mechanical energy conservation. The detailed vertical structure below the mixed layer need not be retained if an approximate rule to give the temperature jump at the base of the layer is substituted. Figure 1 shows a test by the author of such a mixed-layer model, driven by observed atmospheric forcing over a two-year time period. There is reasonable agreement between predicted and observed temperatures on all time scales. Many of the short-term temperature fluctuations result from entrainment of colder water during episodes of mixed-layer deepening. Even the amplitude of the seasonal cycle is directly related to summertime average depth of the mixed layer. These fluctuations cannot be predicted by a constant-thickness mixed layer. It therefore seems that prognostic variable thickness should be included in ocean climate models. It is also physically reasonable to regard momentum as well-mixed to this depth, and the Ekman transport perpendicular to the direction of wind stress should be uniformly distributed through the mixed layer.

The bottom boundary layer is often neglected in ocean climate models. However, studies with resolved ocean eddies indicate that bottom friction can be the dominant mechanism of energy dissipation in some circumstances. Observations and process models suggest that bottom friction can be adequately represented in large-scale models by a quadratic drag law. 
TABLE I. PHYSiCAL PHENOMENA OF OCEANS AND METHODS OF MODELING THEM

\begin{tabular}{|c|c|c|c|c|}
\hline & $\begin{array}{l}\text { Physical } \\
\text { phenomenon }\end{array}$ & $\begin{array}{l}\text { Process model } \\
\text { approach }\end{array}$ & $\begin{array}{l}\text { Usual climatic } \\
\text { model approach }\end{array}$ & $\begin{array}{l}\text { Improved cl imatic } \\
\text { approach }\end{array}$ \\
\hline & $\begin{array}{l}\text { Surface oceanic } \\
\text { mixing }\end{array}$ & $\begin{array}{l}\text { higher-order } \\
\text { closure }\end{array}$ & $\begin{array}{l}\text { constant-thickness } \\
\text { mixed layer }\end{array}$ & $\begin{array}{l}\text { prognostic-thickness } \\
\text { bulk mixed layer } \\
\text { (Heald and Kim 1979) }\end{array}$ \\
\hline \multirow[t]{3}{*}{ (a) } & $\begin{array}{l}\text { Surface ageostrophic } \\
\text { transport }\end{array}$ & vertically resolved & $\begin{array}{l}\text { Ekman transport } \\
\text { in upper level }\end{array}$ & $\begin{array}{l}\text { Ekman transport in } \\
\text { bulk mixed layer }\end{array}$ \\
\hline & $\begin{array}{l}\text { Bottom boundary } \\
\text { layer }\end{array}$ & vertically resolved & free-slip & $\begin{array}{l}\text { quadratic drag law } \\
\text { (Weatherly 1972) }\end{array}$ \\
\hline & $\begin{array}{l}\text { Vertical shearing } \\
\text { instability }\end{array}$ & vertically resolved & & \\
\hline \multirow[t]{3}{*}{ (b) } & $\begin{array}{l}\text { Double-diffusive } \\
\text { effects }\end{array}$ & vertically resolved & $\mathrm{K}_{\mathrm{H}}=$ constant & $K_{H}=f n(R i, N)$ \\
\hline & $\begin{array}{l}\text { Small-scale } \\
\text { vertical mixing }\end{array}$ & vertically resolved & & $\begin{array}{l}\text { (Pacanowsk } i \text { and } \\
\text { Philander } 1981 \text {, } \\
\text { Sarmiento and others } \\
\text { 1976) }\end{array}$ \\
\hline & $\begin{array}{l}\text { Barotropic } \\
\text { instability }\end{array}$ & horizontally & $\begin{array}{l}A_{M}=10^{6} \mathrm{~m}^{2} \mathrm{~s}^{-1} \\
A_{H}=2 \times 10^{3} \mathrm{~m}^{2} \mathrm{~s}^{-1}\end{array}$ & $A_{M}=A_{H}=0\left(10^{3} \mathrm{~m}^{2} \mathrm{~s}^{-1}\right)$ \\
\hline \multirow[t]{3}{*}{ (c) } & $\begin{array}{l}\text { Baroclinic } \\
\text { instability }\end{array}$ & $\begin{array}{l}\text { resolved with } \\
\Delta x=20 \mathrm{~km}\end{array}$ & & $-A_{M}=A_{H}=0\left(10^{3} \mathrm{~m}^{2} \mathrm{~s}^{-1}\right)$ \\
\hline & $\begin{array}{l}\text { Vertical form } \\
\text { drag by eddies }\end{array}$ & & $K_{M}=$ constant & $K_{M}=f n(\Delta T, \Delta u)$ \\
\hline & $\begin{array}{l}\text { Large-scale } \\
\text { advection }\end{array}$ & $\begin{array}{l}\text { done by time-mean } \\
\text { currents }\end{array}$ & $\begin{array}{l}\text { poorly resolved } \\
\text { by } 500 \mathrm{~km} \text {, } \\
5-1 \text { evel grid }\end{array}$ & $\begin{array}{l}\text { moderately resolved by } \\
100 \mathrm{~km}, 10-1 \text { evel grid }\end{array}$ \\
\hline \multirow[t]{3}{*}{ (d) } & $\begin{array}{l}\text { Mixing along } \\
\text { isopycnals }\end{array}$ & $\begin{array}{l}\text { isentropic } \\
\text { coordinates }\end{array}$ & z coordinates & $\begin{array}{l}\text { diffusion along iso- } \\
\text { pycnals }\end{array}$ \\
\hline & $\begin{array}{l}\text { Interaction with } \\
\text { topography }\end{array}$ & sigma coordinates & flat bottom & $\begin{array}{l}\text { variable number of } \\
\text { levels (Bryan 1969) }\end{array}$ \\
\hline & Density relation & Knudsen formula & $\begin{array}{l}\text { linear/quadratic } \\
\text { formula }\end{array}$ & $\begin{array}{l}\text { higher order polynomial } \\
\text { (Bryan and Cox 1972) }\end{array}$ \\
\hline \multirow[t]{3}{*}{ (e) } & $\begin{array}{l}\text { Gravitational in- } \\
\text { stability }\end{array}$ & plume models & $\begin{array}{l}\text { convective adjust- } \\
\text { ment }\end{array}$ & $\begin{array}{l}\text { modified convective } \\
\text { adjus tment }\end{array}$ \\
\hline & Sea-ice dynamics & $\begin{array}{l}\text { viscous/elastic/ } \\
\text { plastic }\end{array}$ & no motion & $\begin{array}{l}\text { empirical ice motion } \\
\text { (Thorndike and Colony } \\
\text { 1982) }\end{array}$ \\
\hline & Ice thermodynamics & $\begin{array}{l}\text { storage of sensible } \\
\text { and latent heat }\end{array}$ & no heat storage & $\begin{array}{l}\text { storage of sensible } \\
\text { and latent heat } \\
\text { (Semtner 1976) }\end{array}$ \\
\hline
\end{tabular}

\section{INTERNAL VERTICAL MIXING}

There are a number of physical processes which mix heat and salt vertically. One of these is an instability caused by vertical shear combined with weak stratification. 0 thers are related to the different molecular diffusivities of heat and salt and to breaking internal waves. All of these phenomena have usually been modeled in climate studies by a constant vertical eddy diffusivity. A number of investigators have suggested functional forms for the dependence of the diffusivity on Richardson number $R i$ and Vaisala frequency $N$. Such formulations should be adopted in future ocean climate studies.

\section{EFFECTS OF MESOSCALE OCEAN EDDIES}

In multilevel models of the ocean, it is necessary to include horizontal diffusion of momentum, heat, and salt to account for the effects of unresolved scales of motion. Failure to prescribe adequately large diffusion coefficients causes unrealistic checkerboard patterns to appear in the solution fields. The larger the grid spacing is in a model, the larger are the required coefficients. A 

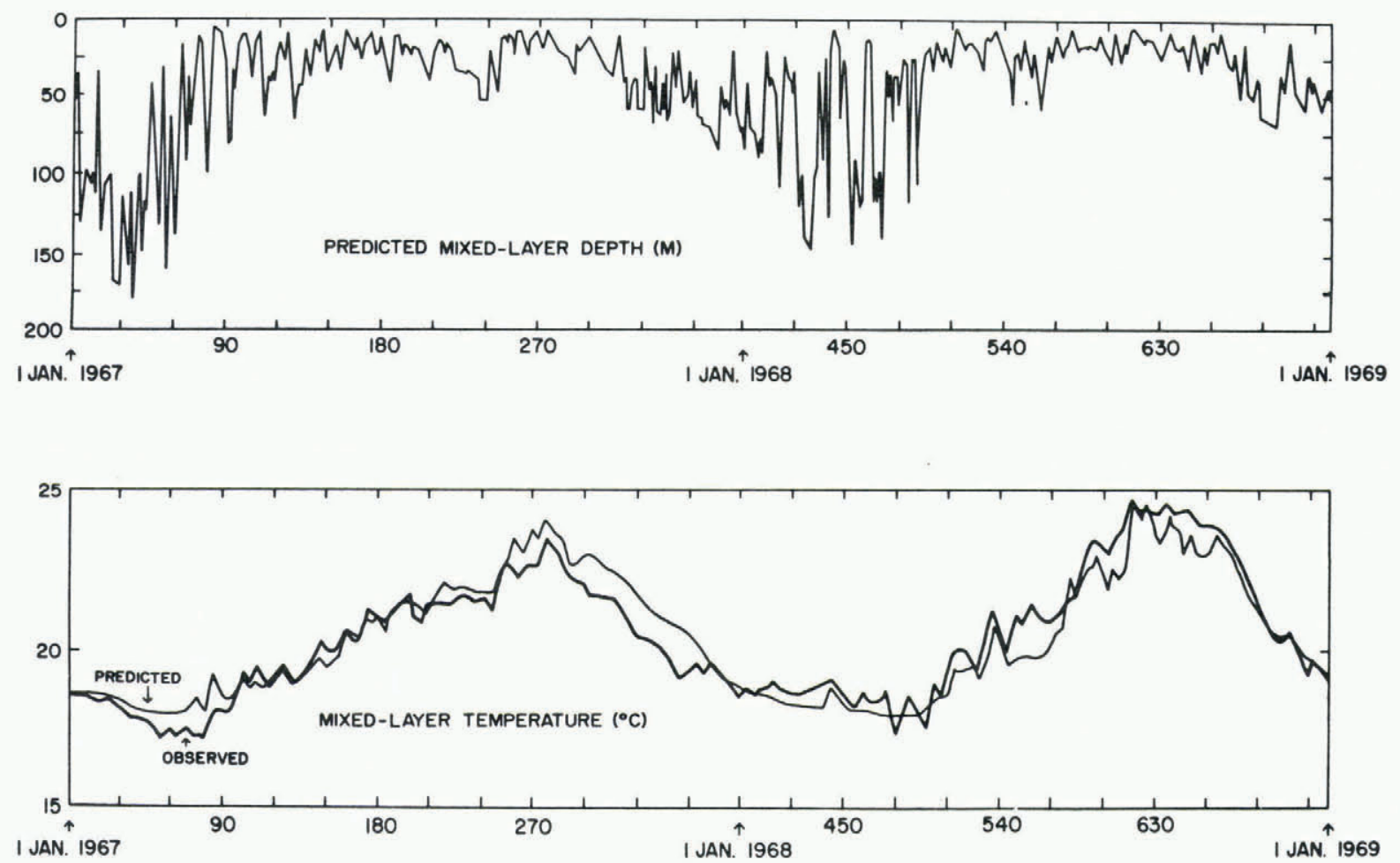

Fig.1. Performance of an embedded mixed-layer model (developed by Heald and Kim 1979) using observed atmospheric forcing from an ocean weather ship. (From Semtner in press.)

number of numerical studies of the world ocean have been carried out with grid spacings of 200 to $500 \mathrm{~km}$. The grid spacing is generally dictated by computational considerations: cutting the horizontal grid size in half increases the number of calculations by a factor of eight or more. Table II indicates the diffusion coefficients that have been used in several. studies. Over the range of grid spacing, the momentum coefficient varies from $10^{5}$ to $10^{6} \mathrm{~m}^{2} \mathrm{~s}^{-1}$ and the the coefficient for heat and salt varies from $10^{3}$ to $2 \times 10^{4} \mathrm{~m}^{2} \mathrm{~s}^{-1}$. Usually, minimal values in a particular study are found by trial and error rather than being dictated by physical considerations. For each of the studies 1 isted in Table II, the values were constant in space and time.

Over the past decade, increased understanding of the physical bas is for horizontal redistributions of momentum, heat, and salt in the ocean by mesoscale eddies has been obtained by observational studies, as well as by numerical studies with horizontal grid spacing adequate to resolve the eddies. The redistributions are complex, in that the order of magnitude and even the sign of the effective diffusion coefficient can change on relatively small spatial scales. Oceanographers who are interested primarily in mesoscale eddies have used this fact to argue that modeling studies with constant diffusion coefficients and without resolved eddies are invalid.

Eddy-resolving models have shown that, in certain types of oceanic flows, instabilities related either to the horizontal structure of the currents or to the vertical shear of the currents lead to downgradient diffusions of heat, with an order of magnitude of $10^{3} \mathrm{~m}^{2} \mathrm{~s}^{-1}$. Observational studies in oceanic currents give similar results (see the last column of Table III). The order of magnitude for eddy diffusion of momentum is also $10^{3} \mathrm{~m}^{2} \mathrm{~s}^{-1}$ ( $\mathrm{cf}$. A $A_{M}$ values in Table III), but the sign can be negative in some cases. Model eddies have also been found to drive deep circulations by processes such as form drag, so that the effective vertical momentum diffusion can be as large as $1 \mathrm{~m}^{2} \mathrm{~s}^{-1}$

The specified values of $A_{H}$ in the global ocean studies of Table II are of magnitude $10^{3} \mathrm{~m}^{2} \mathrm{~s}^{-1}$ (except for one), whereas the specified values for $A_{M}$ are much larger. This suggests that coarse-grid models may distort the predicted motion field more than the thermal field. Putting both coefficients at order $10^{3} \mathrm{~m}^{2} \mathrm{~s}^{-1}$ would require a grid size of $100 \mathrm{~km}$ or less, while still not resolving eddies. At this point, it seems reasonable first to examine global simulations made with the coarse grids and

TABLE II. HEAT AND MOMENTUM DIFFUSION COEFFICIENTS AH AND $A_{M}\left(\mathrm{~m}^{2} \mathrm{~s}^{-1}\right)$, GRID SPACING $\triangle \mathrm{x}(\mathrm{km})$, AND CIRCUMPOLAR TRANSPORT $\triangle \psi\left(10^{6} \mathrm{~m}^{3} \mathrm{~s}^{-1}\right)^{H}$ FROM WORLD OCEAN SIMULATIONS

$\begin{array}{cccccc}\begin{array}{c}\text { Cox } \\ (1975)\end{array} & \begin{array}{c}\text { Takano } \\ (1975)\end{array} & \begin{array}{c}\text { Bryan } \\ \text { and others } \\ (1975)\end{array} & \begin{array}{c}\text { Washington } \\ \text { and others } \\ (1980)\end{array} & \begin{array}{c}\text { Meeh1 } \\ \text { and others } \\ (1982)\end{array} & \begin{array}{c}\text { Han } \\ \text { (in press) }\end{array} \\ 10^{3} & 2.5 \times 10^{3} & 2.5 \times 10^{3} & 2 \times 10^{4} & 2 \times 10^{3} & 2 \times 10^{3} \\ .8 \times 10^{5} & 10^{5} & 0.8 \times 10^{6} & 10^{6} & 10^{6} & 0.8 \times 10^{6} \\ 200 & 400 & 500 & 500 & 500 & 400 \\ 186 & 35 & 22 & 50 & 105 & 86\end{array}$


see how well or badly they reproduce large-scale features of the observed ocean circulation and second to examine the extent to which a grid-size reduction may improve the representation of eddy effects.

Figure 2 shows the differences between computed and observed sea surface temperature (SST) from two coupled ocean-atmosphere models. One might assume that the large positive errors in SST at high latitudes result from a large grid size. However, the main source of error in the Geophysical Fluid Dynamics Laboratory (GFDL) simulation is misrepresentation of southern-hemisphere winds by the atmospheric model, while in the National Center for Atmospheric Research (NCAR) simulation it is an overly large value of $A_{H}$.

\section{GFDL}

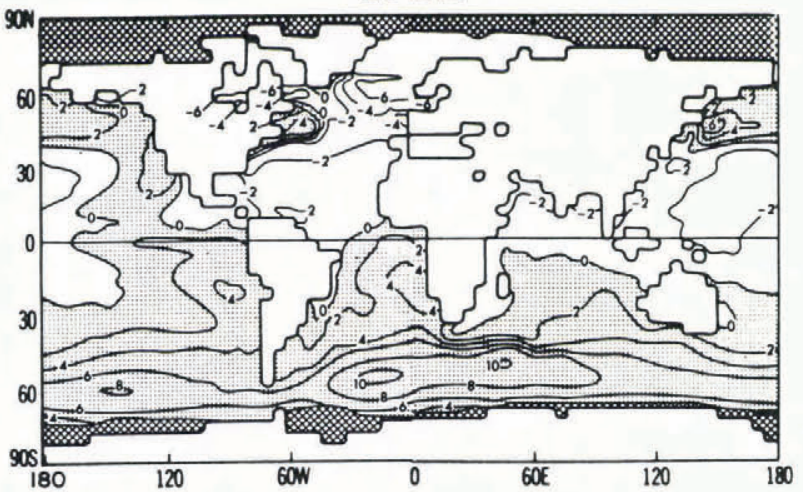

NCAR

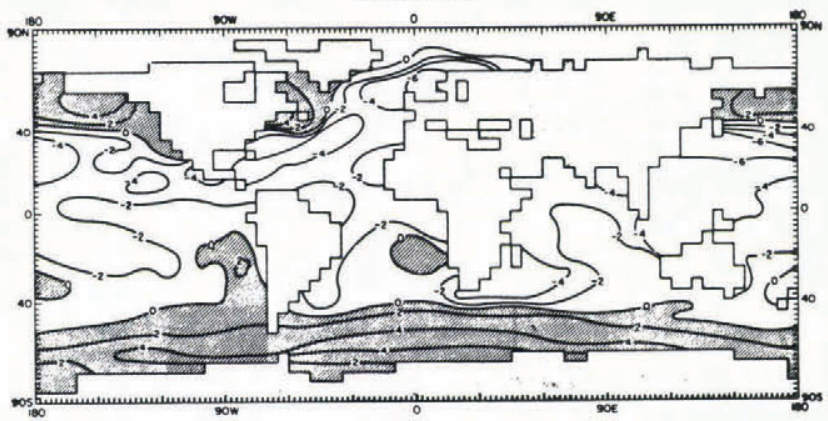

Fig.2. Annual average SST differences (computed minus observed) from coupled model studies at GFDL and at NCAR. (From Washington and others 1980.)

A fairer assessment of ocean model performance can be made by looking at cases with observed atmospheric forcing and $A_{H}$ of order $10^{3} \mathrm{~m}^{2} \mathrm{~s}^{-1}$. Figure 3 shows fields from a global model driven by observed winds but by surface heat fluxes computed from a zonally invariant atmospheric temperature. The SST in the top panel would cons ist of horizontal lines in the absence of ocean circulation. Obviously, circulation is important, and many features of the predicted SST qualitatively resemble those observed. The middle panel shows a rather realistic pattern of equatorial and polar upwelling, together with mid-latitude downwelling. The bottom panel shows significant surface heat fluxes, which are required to balance oceanic heat transport.

Figure 4 shows simulated heat transport and heat storage from an NCAR model with observed forcing and reduced $A_{H}$, versus the observed quantities. Except for a diffusive contribution which is still too large in high latitudes, the meridional heat transport is well modeled in terms of both the annual mean and the seasonal cycle. Seasonal heat storage and meridional heat transport by individual oceans are fairly well modeled. Since heat transport and
Temperature distribution at a depth of $20 \mathrm{~m}$.

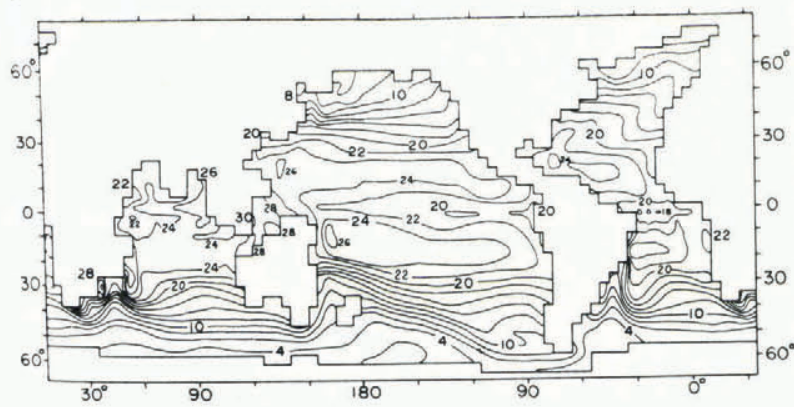

Vertical component of velocity at a depth of $70 \mathrm{~m}$.

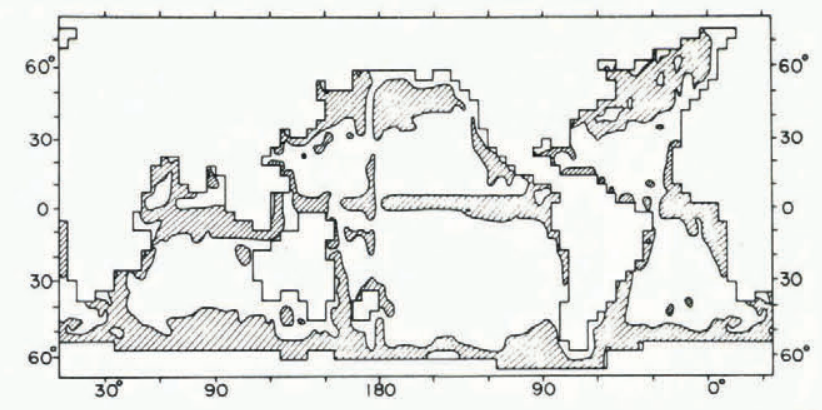

Heat flux (1y $\left.d^{-1}\right)$ computed from the surface water temperature.

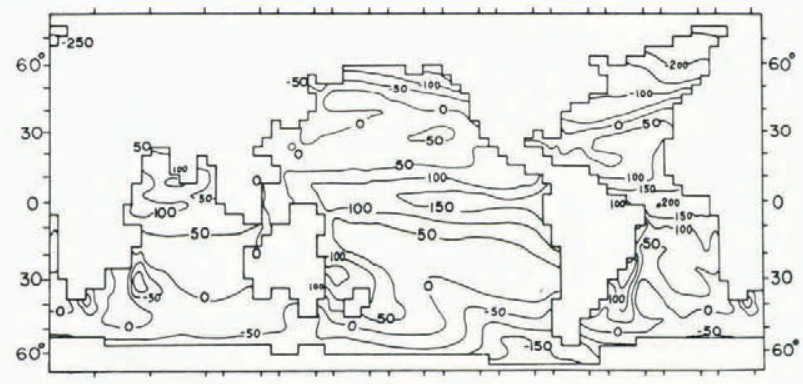

Fig.3. Predicted fields from the world ocean model of Takano (1975).

heat storage are the major components of the oceanic influence on SST and climate, the ability of the coarse grid models to simulate the ocean properly in climate studies may be better than eddy modelers have suggested. A fairly realistic simulation of SST from another coarse-grid model has been obtained by Han (in press).

The proper representations of heat transport and storage in the coarse grids may be due to the dominant effects of meridional overturning and mixed-layer heat capacity, respectively. As indicated earlier, the momentum diffusion coefficient AM can be expected to misrepresent horizontal circulation in coarse grids. Table II gives values of the mass transport by the Antarctic Circumpolar Current through the Drake Passage. It is clear that all the simulations give low values relative to the observed value of $(185 \pm 35) \times 10^{6} \mathrm{~m}^{3} \mathrm{~s}^{-1}$, except for one study with a finer grid and significantly smaller $A_{M}$ than the others. However, models with large $A_{M}$ do show similar patterns of horizontal circulation to those of the finer grid and of the real ocean (Fig.5). The study with the fine grid still underestimates the observed strength of midlatitude gyres $\left(\approx 100 \times 10^{6} \mathrm{~m}^{3} \mathrm{~s}^{-1}\right)$, al though the meridional transport is better represented (Fig.6). 

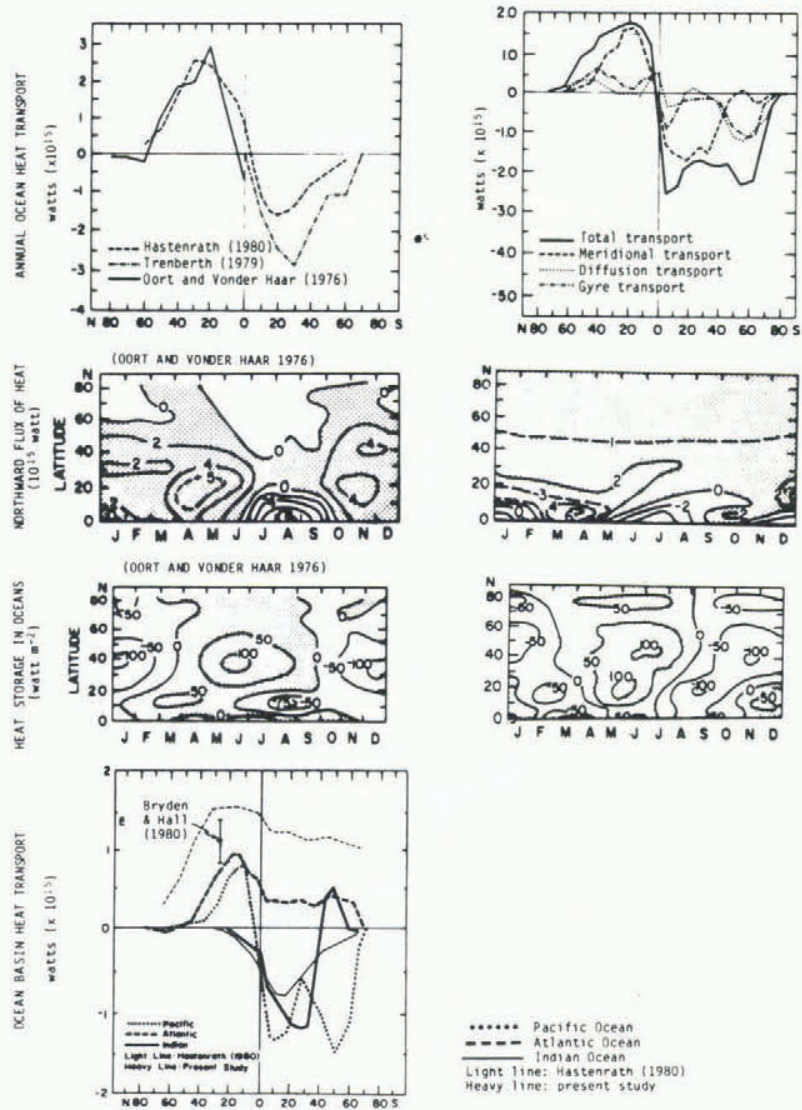

Fig.4. Aspects of oceanic heat transport and heat storage, as observed (left) and as predicted (right) in a model driven by atmospheric data. The bottom panel shows the predicted and observed transports in individual ocean basins. (From Meehl and others 1982.)
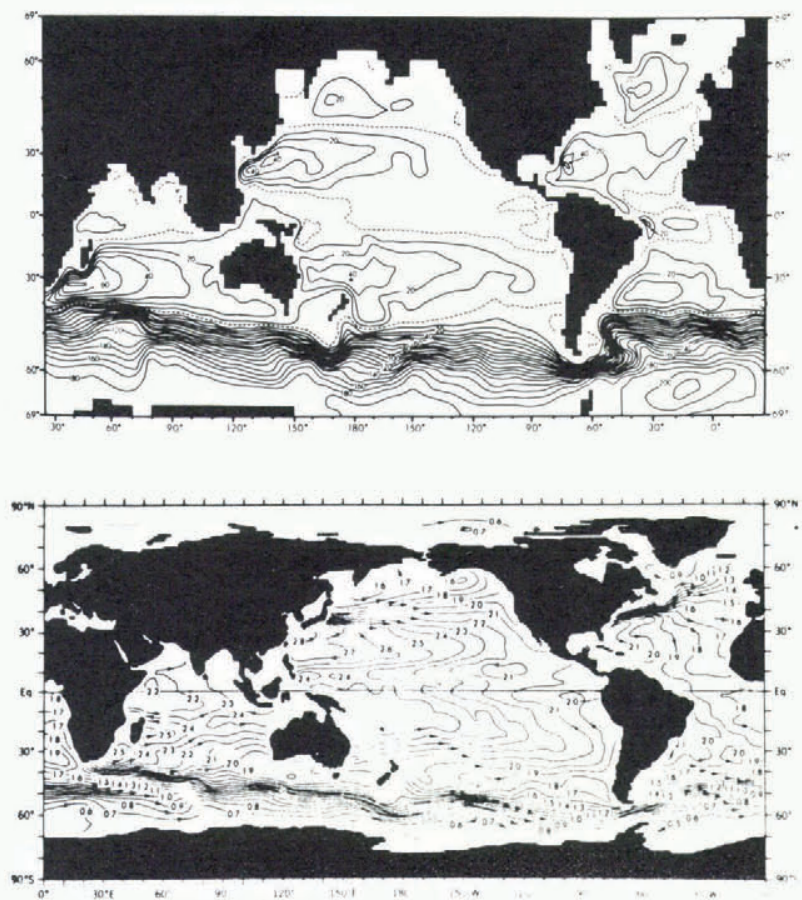

Fig.5. Above: streamlines of mass transport from the world ocean study of Cox (1975). Below: streamlines of upper ocean currents inferred from the density field by Levitus (1982).
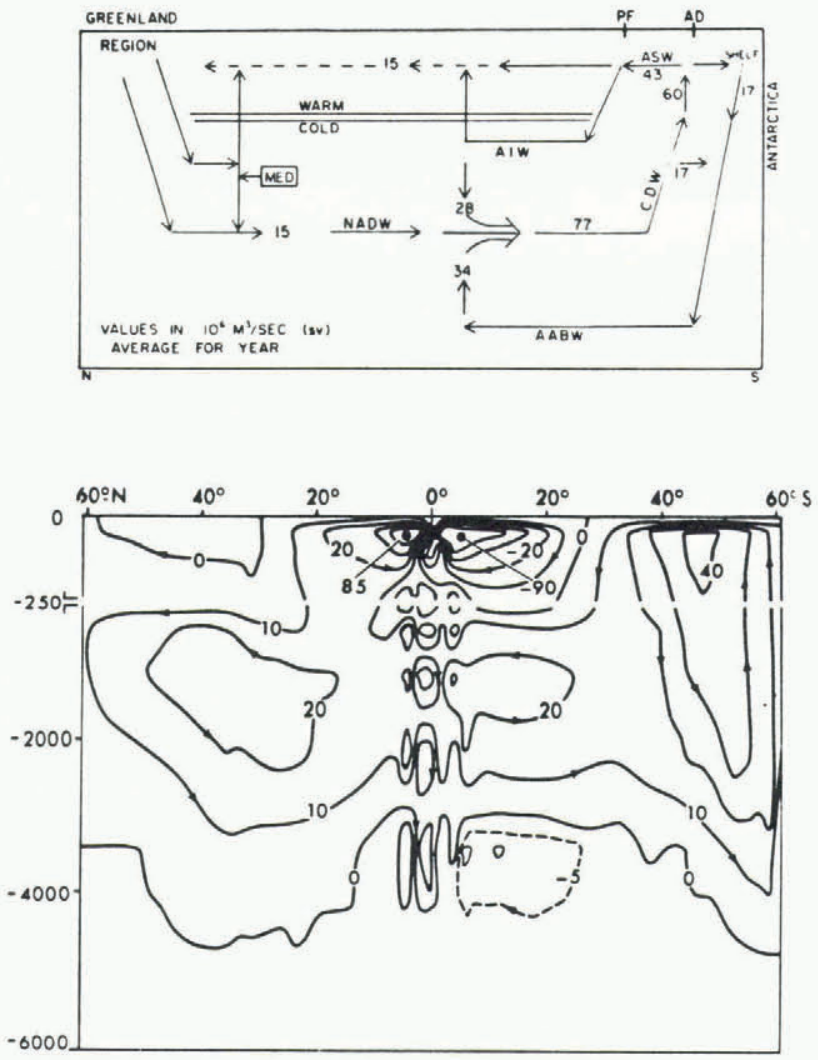

Fig.6. (above) Schematic view of the observed meridional circulation according to Gordon (1971) and (below) stream function of the meridional circulation in the model of Cox (1975).

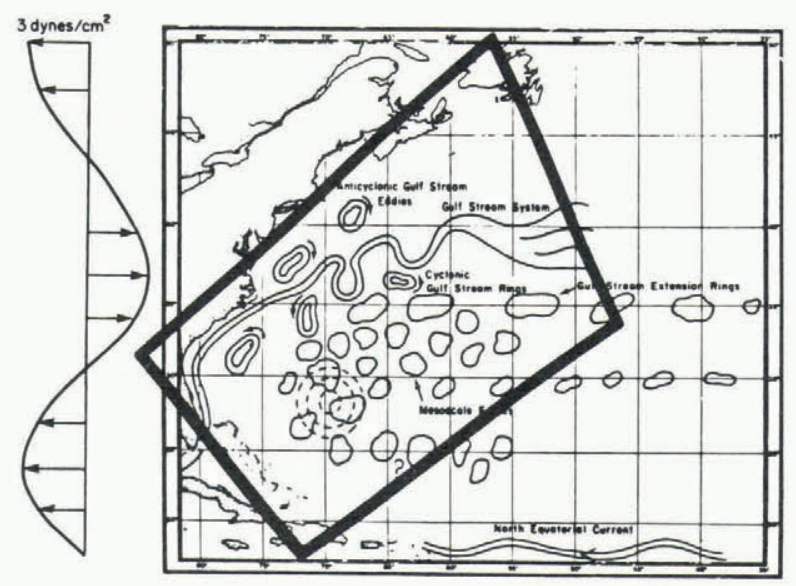

Fig.7. Schematic representation of phenomena of the Gulf Stream, as well as the model domain (bounded by the heavy line) and the wind stress used in the eddy resolving study of Semtner and Mintz (1977).

Let us now turn to the question of whether further reductions in grid size and in $A_{M}$ without resolving eddies will adequately portray the horizontal circulation. Figure 7 shows the schematic design of an eddy-resolving study of the Gulf Stream. Figure 8 shows simulated fields of surface streaml ines (height) and surface temperatures as follows: left, instantaneous fields from a $37 \mathrm{~km}$ grid; middle, timeaveraged fields from a $37 \mathrm{~km}$ grid; and right: steady fields from a $75 \mathrm{~km}$ grid using $A_{M}=A_{H}=10^{3} \mathrm{~m}^{2} \mathrm{~s}^{-1}$. From the point of view of large-scale influence on cl imate, the middle and left fields do not differ 


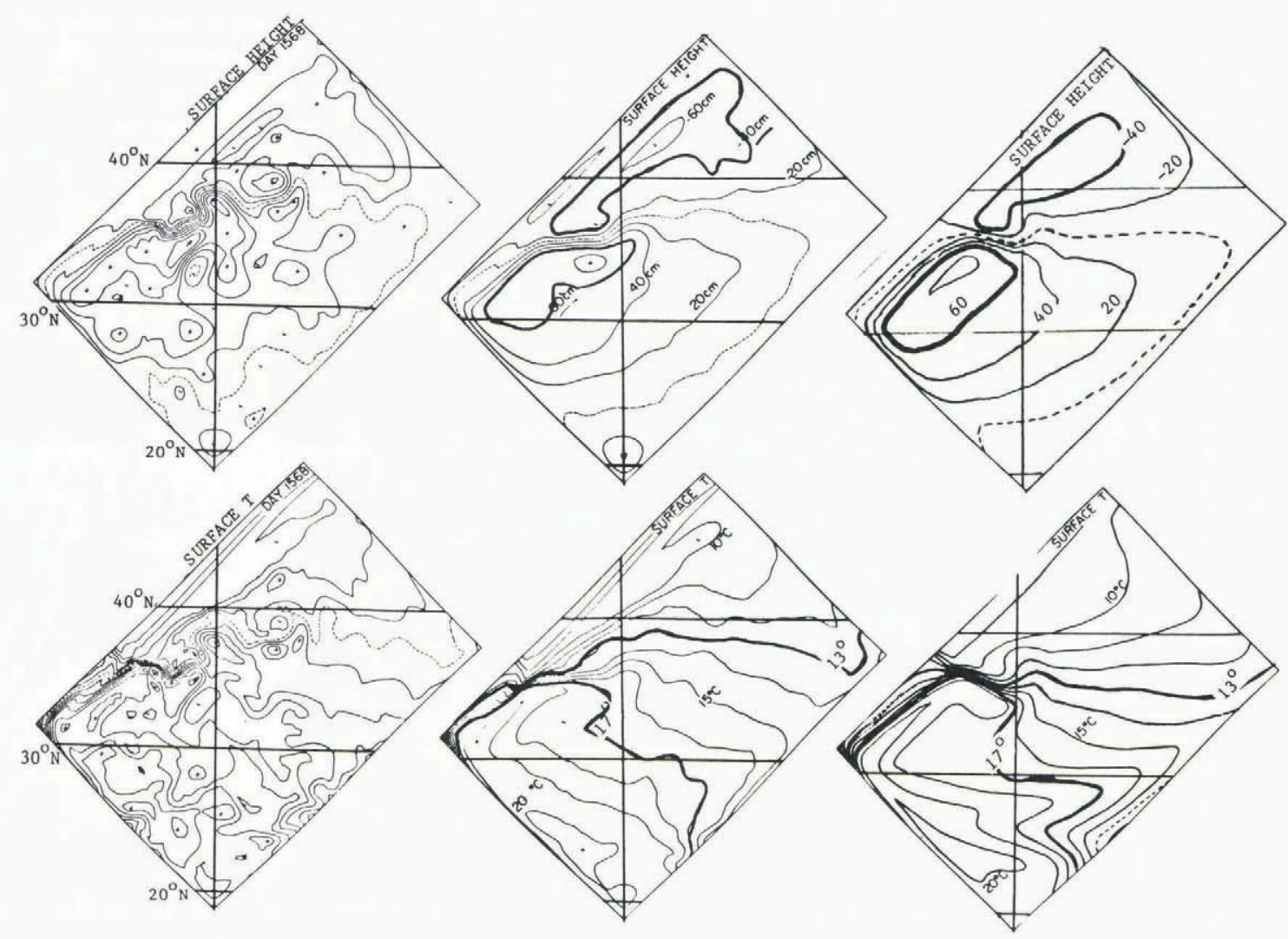

Fig.8. Left: maps of instantaneous surface height and surface temperature in the eddy resolving simulation of Semtner and Mintz (1977); center: time-averaged fields from that simulation; right: the steady fields from a coarse-grid simulation using $A_{H}=A_{M}=10^{3} \mathrm{~m}^{2} \mathrm{~s}^{-1}$.

TABLE III. SOME OCEANIC HORIZONTAL DIFFUSIVITIES FROM OBSERVATIONAL (0) AND MODEL (M) STUDIES

\begin{tabular}{llcc} 
Current system & \multicolumn{1}{c}{ Investigation } & $A_{M}\left(\mathrm{~m}^{2} \mathrm{~s}^{-1}\right)$ & $A_{H}\left(\mathrm{~m}^{2} \mathrm{~s}^{-1}\right)$ \\
\hline $\begin{array}{c}\text { Gulf Stream and } \\
\text { recirculation }\end{array}$ & (0) Bryden (1982) & $-9 \times 10^{3}$ & $11 \times 10^{3}$ \\
$\begin{array}{c}\text { westward } \\
\text { interior flow }\end{array}$ & (M) Semtner and Mintz (1977)* & --- & $3-10 \times 10^{3}$ \\
$\begin{array}{l}\text { equatorial } \\
\text { currents }\end{array}$ & (M) Freeland and others (1975) & --- & $0.8 \times 10^{3}$ \\
$\begin{array}{l}\text { Circumpolar } \\
\text { Current }\end{array}$ & (M) Semtner and Holland (1980) & $2 \times 10^{3}$ & $1-3 \times 10^{3}$ \\
& (O) Bryden (1979) & & $2-10 \times 10^{3}$ \\
& (M) McWilliams and others (1978) & $-3 \times 10^{3}$ & $0.6 \times 10^{3}$ \\
\end{tabular}

* based on unpublished further analysis.

much from each other. (In the absence of circulation, the surface height would be constant and the temperature would vary linearly with latitude from 30 to $0^{\circ} \mathrm{C}$. .)

Figure 9 shows instantaneous fields in another eddy-resolving experiment, this time for an equatorial simulation. Figure 10 compares several time-averaged fields versus the quasi-steady ones obtained by setting $A_{M}=A_{H}=2 \times 10^{3} \mathrm{~m}^{2} \mathrm{~s}^{-1}$. Once again the comparison is favorable from a large-scale viewpoint. Such results suggest that much of the time-averaged oceanic circulation can be obtained from models with sufficiently fine grid to allow an $A_{M}$ of order $10^{3}$. Additional refinements, including local sign changes of $A_{M}$ and enlarged value of vertical viscosity $K_{M}$ can be included on the basis of developing theoretical understanding.

\section{LARGE-SCALE TRANSPORTS}

A related issue concerning grid size is whether oceanic time-mean fields can be adequately depicted. Figure 5 gives some indication that a $200 \mathrm{~km}$ grid size adequately represents the structure of the Antarctic Circumpolar Current (after taking account of the Mercator stretching of the model field). Figure 8 indicates that $75 \mathrm{~km}$ grid spacing allows western boundary features to be depicted. The scale of the simulated Gulf Stream jet is about $150 \mathrm{~km}$, thereby indicating an upper 1 imit for resolution. Thus the $100 \mathrm{~km}$ grid size required for realistic eddy viscosity is adequate for depicting the time-mean fields. Above $150 \mathrm{~km}$, some degradation in certain regions can be expected.

In the real ocean, eddy diffusion may act more along isopycnal surfaces than purely in the hori- 


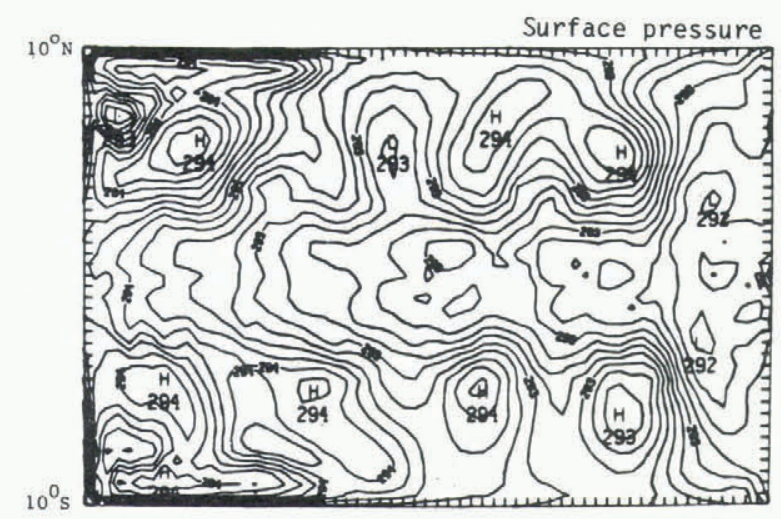

$T$ at $95 \mathrm{~m}$

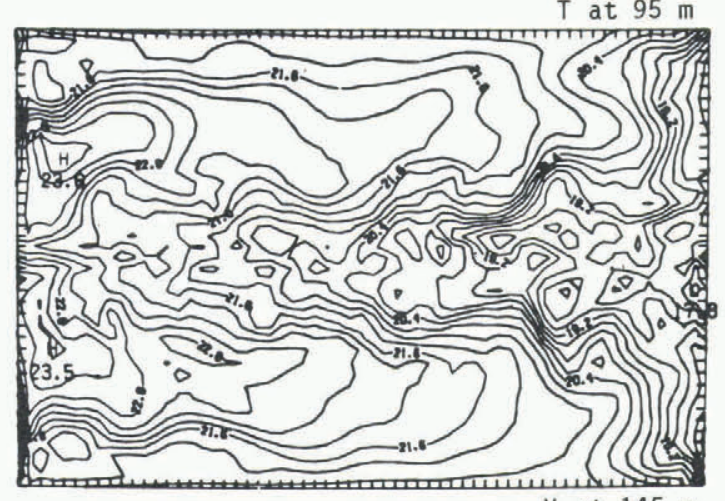

V at $145 \mathrm{~m}$

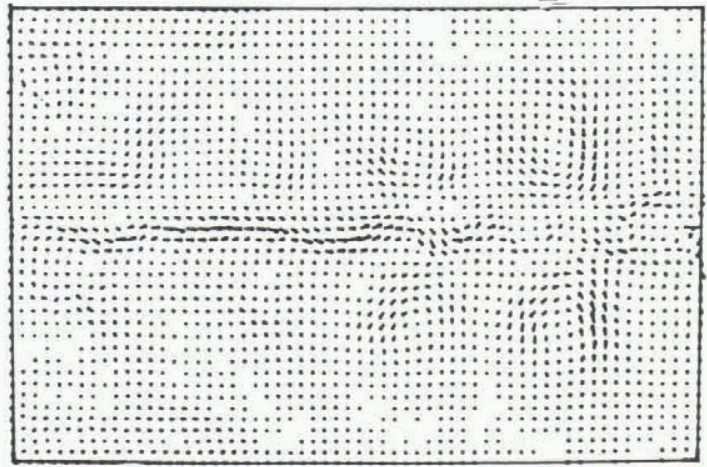

Fig.9. Instantaneous fields from the eddy-resolving equatorial experiment of Semtner and Holland (1980).

zontal. The choice of isentropic coordinates gives a better treatment of such diffusion but involves formidable numerical problems. For improved ocean climate modeling, continued use of $z$ coordinates for dynamics but adoption of diffusion operators oriented along isopycnals may be the best compromise.

Topography is handled in atmospheric models by the use of sigma coordinates, whereby the lowest coordinate surface follows the terrain. The method tends to break down for the oceans, because the scale of the topography relative to ocean depth is too large. In some ocean climate models, a flat bottom is assumed, but this can distort currents, thermohaline circulation, and water-mass formation. The method of using $z$ coordinates but allowing a variable number of vertical levels is probably preferable.

\section{MISCELLANEOUS HIGH-LATITUDE EFFECTS}

Brief mention should be made that accurate representation of the nonlinear equation of state for seawater is important, especially in polar regions. Also, the usual method of dealing with gravitational instability by convective adjustment may treat bottom-water
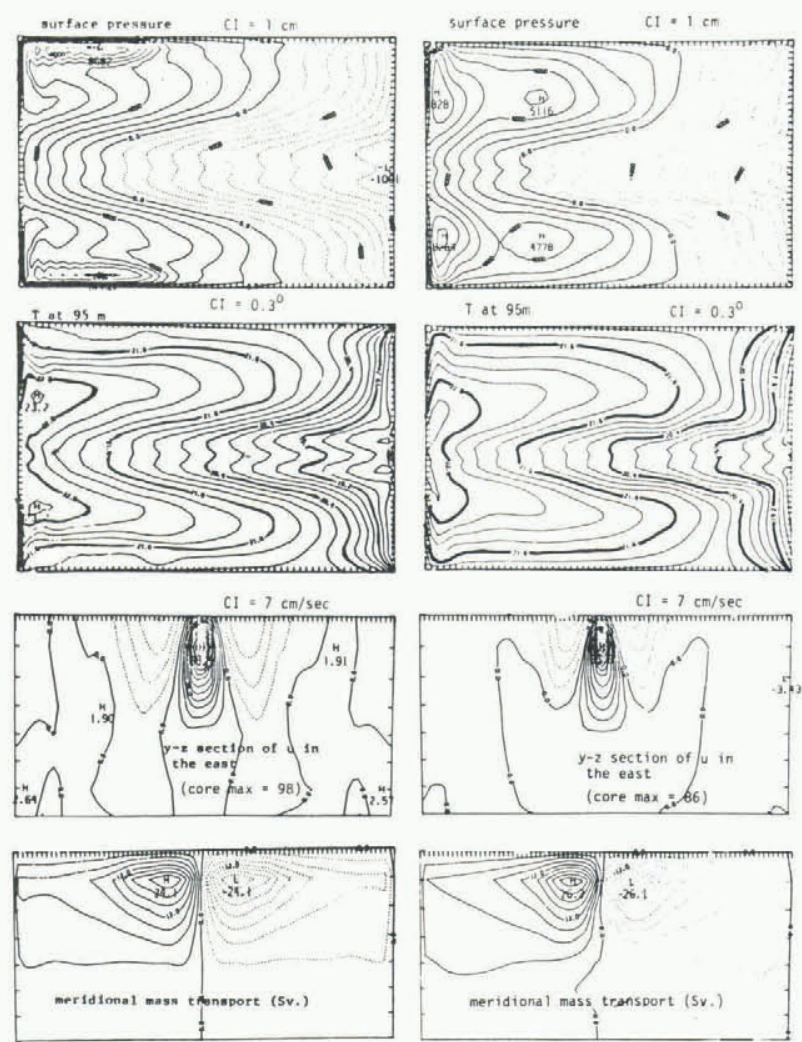

Fig.10. Left: Time-averaged fields from the eddy resolving experiment of Semtner and Holland (1980). Right: instantaneous fields obtained from introducing lateral diffusion of heat and momentum (using $A_{H}=A_{M}=2 \times 10^{3} \mathrm{~m}^{2} \mathrm{~s}^{-1}$ ) and running the experiment an additional 150 days.

formation inadequately and require augumentation by plume models in some key regions. Finally, the thermodynamics and dynamics of sea ice, which are now treated rather poorly in most climate models, need to be improved.

\section{CONCLUSIONS}

To provide more accurate oceanic simulations in cl imate studies, a number of improved parameterizations have been suggested. Many of these are straightforward and cause little increase in computation. The largest increase would come from suggested grid-size reductions to allow more real istic eddy viscosity and smaller horizontal scales in the predicted fields. The need for resolving eddies in climate studies, as suggested by eddy modelers, has been disputed. The suggested grid-size reductions without resolving eddies will be feasible as faster computers become available in the mid to late 1980s. In the meantime, simulations with coarse grids can meaningfully portray many aspects of ocean circulation.

\section{ACKNOWLEDGEMENT}

The National Center for Atmospheric Research is sponsored by the US National Science Foundation.

\section{REFERENCES}

Bryan K 1969 A numerical method for the study of the circulation of the world ocean. Journal of Computational Physics 4: 347-376

Bryan K, Cox M D 1972 An approximate equation of state for numerical models of ocean circulation. Journal of Physical oceanography 2: 510-514 
Bryan K, Manabe S, Pacanowski R C 1975 A global ocean-a tmosphere $c l$ imate model. Part II. The oceanic circulation. Journal of Physical oceanography 5: 30-46

Bryden H L 1979 Poleward heat flux and conversion of available potential energy in Drake Passage. Journal of Marine Research 37: 1-22

Bryden H L 1982 Sources of eddy energy in the Gulf Stream recirculation region. Journal of Marine Research 40: 1047-1068

Bryden H L, Hall M M 1980 Heat transport by currents across $25^{\circ} \mathrm{N}$ latitude in the Atlantic Ocean. Science 207: 884-885

Eox M D 1975 A baroclinic numerical model of the world ocean: preliminary results. In Numerical models of ocean circulation. Washington, DC, National Academy of Sciences: 107-120

Freeland H, Rhines P, Rossby T 1975 Statistical observation of the trajectories of neutrally buoyant floats in the North Atlantic. Journal of Marine Research 33: 383-404

Gordon A L 1971 0ceanography of Antarctic waters. In Reid J L (ed) Antarctic oceanology I: 169-203 (Antarctic Research Series 15)

Han $Y-J$ In press A numerical world ocean general circulation model. Part II. A baroclinic experiment. Dynamics of Atmospheres and Oceans

Hastenrath S 1980 Heat budget of tropical ocean and atmosphere. Journal of Physical Oceanography 10: $159-170$

Heald R C, Kim J-W 1979 Parameterization of the oceanic mixed layer for use in general circulation models. Corvallis, Oregon State University. Climatic Research Institute (Report 10)

Levitus S 1982 Climatological atlas of the world ocean. Rockville, MD, US Department of Commerce (NOAA Professional Paper 13)

McWilliams J C, Holland W R, Chow J H S 1978 A description of numerical Antarctic circumpolar currents. Dynamics of Atmospheres and oceans 2: 213-291

Meeh1 G A, Washington W M, Semtner A J Jr 1982 Experiments with a global ocean model driven by observed atmospheric forcing. Journal of Physical oceanography 12: 301-312

Oort A H, Vonder Haar T H 1976 On the observed annual cycle in the ocean-atmosphere heat balance over the northern hemisphere. Journal of Physical oceanography 6: 781-800

Pacanowski R C, Philander S G H 1981 Parameterization of vertical mixing in numerical models of tropical oceans. Journal of Physical Oceanography 11: $1443-1451$

Sarmiento J L, Geely H W, Moore W S, Bainbridge A E, Broecker W S 1976 The relationship between vertical eddy diffusion and buoyancy gradient in the deep sea. Earth and Planetary Science Letters 32: 357-370

Semtner A J Jr 1976 A model for the thermodynamic growth of sea ice in numerical investigations of climate. Journal of Physical oceanography 6: 379-389

Semtner A J Jr In press Development of efficient, dynamical ocean-atmosphere models for climatic studies. Journal of Climate and Applied Meteorology

Semtner A J Jr, Holland W R 1980 Numerical simulation of equatorial ocean circulation. Part I. A basic case in turbulent equilibrium. Journal of Physical Oceanography 10: 667-693

Semtner A J Jr, Mintz Y H 1977 Numerical simulation of the Gulf Stream and midocean eddies. Journal of Physical oceanography 7: 208-229

Takano K 1975 A numerical simulation of the world ocean circulation: preliminary results. In Numerical models of ocean circulation. Washington, DC, National Academy of Sciences: 121-129

Thorndike.A S, Colony R 1982 Sea ice motion in response to geostrophic winds. Journal of Geophysical Research 87: 5845-5852
Trenberth K E 1979 Mean annual poleward energy transports by the oceans in the southern hemisphere. Dynamics of Atmospheres and Oceans 4: $57-64$

Warren B A, Wunch C (eds) 1981 Evolution of physical oceanography. Cambridge, MA, MIT Press

Washington W M, Semtner A J Jr, Meehl G A, Knight D J, Mayer T A 1980 A general circulation experiment with a coupled atmosphere, ocean, and sea ice model. Journal of Physical Oceanography 10: 1887-1908

Weatherly G L 1972 A study of the bottom boundary layer of the Florida Current. Journal of Physical oceanography 2: 54-72 